\title{
SPEECH HABIT AS BASIS OF SPEAKER'S SPEECH PORTRAIT (BASED ON BRITISH POLITICAL DISCOURSE)
}

\author{
Galina G. Matveeva \\ Southern Federal University, Rostov-on-Don, Russian Federation \\ Irina A. Zyubina \\ Southern Federal University, Rostov-on-Don, Russian Federation
}

\begin{abstract}
The study which results are summarized in the article is performed on the basis of implicit pragmalinguistics. In particular, some features of grammatical forms use in accordance with the emotiveorientated speech strategy "Participation / non-participation of communicants in a speech event" are considered in the work. This strategy is implemented in three dimensions: personal, social, and objective. To actualize the dimensions an addresser makes a choice of particular grammatical forms. When counting a number of addresser text choices of all three planes we get a picture of his preferences which reflects his usual speech behavior and which can be represented as his speech portrait. In the study the fragments of speech portraits of four representatives of the House of Lords in the Parliament and the Prime Minister of Great Britain are reconstructed and characterized, they are created on the basis of their discourses research which is carried out using probabilistic and statistical method and the method of modified content analysis. It is found out that speech portrait interpretation of an addresser leads to identification of speaker's individual traits, and their interpretation leads to diagnosing his personal traits which are found from an analysis of particular discourse uttered by a particular speaker "here and now".
\end{abstract}

Key words: pragmalinguistics, discourse, speech portrait, speech habit, use of grammatical forms, category of selection.

\section{РЕЧЕВАЯ ПРИВЫЧКА КАК ОСНОВА РЕЧЕВОГО ПОРТРЕТА ГОВОРЯЩЕГО (НА МАТЕРИАЛЕ БРИТАНСКОГО ПОЛИТИЧЕСКОГО ДИСКУРСА)}

\author{
Галина Григорьевна Матвеева
}

Южный федеральный университет, г. Ростов-на-Дону, Российская Федерация

\author{
Ирина Анатольевна Зюбина \\ Южный федеральный университет, г. Ростов-на-Дону, Российская Федерация
}

\begin{abstract}
Аннотация. Исследование, результаты которого обобщены в статье, выполнено в русле скрытой прагмалингвистики. В частности, рассматриваются некоторые особенности выбора говорящим грамматических форм в соответствии с актуализируемой эмотивно-ориентированной речевой стратегией «участие / неучастие коммуникантов в речевом событии». Показано, что данная стратегия реализуется в трех планах: личном, социальном и предметном. Установлено, что для актуализации каждого из них говорящий осуществляет выбор определенных грамматических форм, количественный подсчет которых позволил, во-первых, выявить предпочтения говорящего, отражающие его привычное речевое поведение, во-вторых, представить их в виде его речевого портрета. В статье реконструированы и охарактеризованы фрагменты речевых портретов четырех женщин-парламентариев (представительниц палаты лордов) и премьер-министра Великобритании, которые созданы на основе исследования их дискурсов, проведенного с применением вероятностно-статис-
\end{abstract}


тического метода и метода модифицированного контент-анализа. Выявлено, что интерпретация речевого портрета говорящего приводит к идентификации индивидуальных черт его речи, а их интерпретация - к диагностированию его личностных черт, которые отражаются в конкретном тексте, произнесенном им «здесь и сейчас», и которые обнаруживаются при его прагмалингвистическом анализе.

Ключевые слова: прагмалингвистика, дискурс, речевой портрет, речевая привычка, употребление грамматических форм, категория выбора.

Исследование, результаты которого обобщены в статье, выполнено в рамках прагмалингвистического подхода к анализу речевого поведения политиков на материале их дискурсов. Термин «дискурс» [6] актуален при анализе речи, так как этим термином обозначается особое использование языка для выражения индивидуального специфического менталитета. Оно влечет за собой активизацию некоторых черт языка и, в частности, особой грамматики. Дискурс индивида характеризует не только события, но и обстоятельства, сопутствующие этим событиям, его участников, оценивание ими этого события и, наконец, сопровождающую дискурс перформативную информацию. Некоторые из этих особенностей дискурса можно извлечь из анализа используемых говорящим грамматических форм и грамматических категорий.

\section{1}

В работах по скрытой прагмалингвистике [1; 5] особенности употребления говорящим некоторых грамматических форм изучаются в рамках актуализации речевых стратегий скрытого воздействия отправителя текста на его получателя. Скрытые речевые стратегии подразделяются на группы: эмотивно-ориентированные и конативно-ориентированные [5, c. 96-262].

Обратимся к эмотивно-ориентированной речевой стратегии «участие / неучастие коммуникантов в речевом событии». Она реализуется в трех планах: личном, социальном и предметном, для актуализации которых говорящий выбирает определенные грамматические формы.

Реализуя названную стратегию в личном плане, говорящий актуализирует участие в речевом событии либо отправителя текста, которым является он сам, либо его получателя. Например:
(1) This morning I had meetings with ministerial colleagues and others, and in addition to my duties in this House I shall have further such meetings later today $(\mathrm{HCH})$.

(2) He referred to me as the second woman Prime Minister $(\mathrm{HCH})$.

(3) My hon. Friend has made my day, and I hope that I can make his day by wishing him a very happy birthday $(\mathrm{HCH})$.

(4) I welcome the comments the right hon. Gentleman made about Prime Minister's questions $(\mathrm{HCH})$.

(5) Hon. Members! More! (HCH). $(\mathrm{HCH})$.

(6) Well - it just keeps making us Prime Minister

(7) Perhaps I could put the right hon. Gentlemanstraight $(\mathrm{HCH})$.

Как свидетельствуют примеры, для указания на отправителя или получателя текста выбираются следующие грамматические формы: эксклюзивные личные местоимения (пример 1), косвенные формы эксклюзивных личных местоимений (пример 2) и соответствующие им притяжательные местоимения (пример 3), существительные в функции эксклюзивных личных местоимений (пример 4), обращения (пример 5), вводные члены предложения, особенно модальные слова и некоторые наречия, имеющие модально-оценочное значение (примеры 6, 7). Таким образом, говорящий актуализирует свое личное участие в процессе высказывания.

Социальный план рассматриваемой речевой стратегии проявляется в том, что в акте коммуникации говорящий указывает на обоих участников общения: отправителя, которым является он сам, и получателя текста. Например:

(8) We can now get on with the essential job of renewing our nuclear deterrent $(\mathrm{HCH})$.

(9) It is this Government who will change that and this Government who are putting more into building more homes to ensure that young people have a better opportunity to get on the housing ladder $(\mathrm{HCH})$. 
(10) It is not about austerity; it is about ensuring that we have an economy that works for everyone $(\mathrm{HCH})$.

(11) I was concerned to make sure that nobody should be stopped and searched on the streets of this country because of the colour of their skin $(\mathrm{HCH})$.

(12) I absolutely confirm that, yes, the United Kingdom will leave the European Union, but the United Kingdom is not leaving Europe and our co-operation will continue $(\mathrm{HCH})$.

Речевыми сигналами социального плана являются следующие грамматические формы: инклюзивные личные местоимения (пример 8), существительные, соответствующие инклюзивным местоимениям (пример 9), неопределенные и отрицательные местоимения (примеры 10, 11), лексемы с семой антропонима типа 'человечество', ‘народ' и др. (пример 12). Таким образом автор актуализирует участие в речевом событии отправителя, которым является он сам, и получателя текста.

Предметный план речевой стратегии «участие / неучастие коммуникантов в речевом событии» связан с тем, что говорящий акцентирует внимание получателя текста на объективности протекания речевого события, поскольку оно не зависит от участия / неучастия в нем коммуникантов. Например:

(13) The answer for people who are in work and struggling and for those who want to get into work is to have a strong economy that delivers jobs, and wellpaid jobs in particular $(\mathrm{HCH})$.

(14) As my hon. Friend also said, a significant number of trade deals have already been signed, which shows that... $(\mathrm{HCH})$.

Набор актуализаторов предметного плана включает речевые сигналы наличия действующего лица, к которому нельзя отнести участников речевого события (пример 13), пассив, при котором действующее лицо или предмет выражены или выводятся из контекста, но не участвуют в речевом событии (пример 14). В речевом событии говорящий не актуализирует ни участие отправителя, которым является он сам, ни участие получателя текста. Он акцентирует внимание получателя текста на объективности протекания речевого события помимо воли участников коммуникации.
Кроме указанных средств актуализации каждого из выделенных планов речевой стратегии «участие / неучастие коммуникантов в речевом событии», других способов отражения участия коммуникантов в речевом событии нет. Поэтому если в тексте определенной длины произвести подсчет количества выбранных говорящим речевых маркеров личного, социального и предметного планов рассматриваемой стратегии, то можно получить картину его предпочтений, которая отражает его привычное речевое поведение и которая может быть представлена в виде его речевого портрета.

Понятие речевого портрета возникло в связи с появлением и формированием такого направления, как прагмалингвистика. Одной из главных ее категорий является категория выбора. Каждый конкретный автор в конкретной ситуации выбирает при создании конкретного текста набор конкретных речевых сигналов определенных форм грамматических категорий, хотя конкретный речевой сигнал грамматической категории не представляет интеpeca c точки зрения его воздействия в данный конкретный момент и в данном конкретном месте. Можно говорить о воздействующем наборе речевых сигналов некоторой грамматической категории в дискурсе отправителя текста. Эти наборы речевых сигналов свидетельствуют об индивидуальности автора текста, так как отражают его речевой опыт.

Он накоплен говорящим с возрастом, при получении образования, в профессиональной деятельности, в процессе общения в определенном социальном кругу, обусловлен традициями семьи, национальными традициями, социальным статусом и социальными ролями и др. Речевой опыт актуализируется в предпочтительном выборе речевых сигналов определенной грамматической категории.

Такой выбор является результатом речевой привычки говорящего, которая понимается как «автоматический неосознаваемый выбор адресантом форм грамматических и текстуальных категорий» [4, с. 253]. Это автоматизированное, неосознаваемое речевое поведение индивида связано с реализацией его потребностей здесь и сейчас. Для журналиста, например, это потребность в передаче определенных фактов, информации, потребность 
в ее точности, броскости, новизне и т. п. Со временем такой выбор журналиста становится привычным, то есть превращается в автоматическую и неосознаваемую речевую привычку. Речевые привычки помогают установить идиостиль и идиолект автора, описать его речевой реал-имидж и составить его речевой портрет. В речевом портрете всегда скрыта речевая привычка автора, которую можно обнаружить на основании речевых сигналов актуализации им грамматических форм. Учет и оформление картины актуализации речевых сигналов в виде таблиц и представляет собой фрагмент прагмалингвистического речевого портрета говорящего, который трактуется как картина уподобления человека речевым условиям его интеллектуального, волевого, эмоционального, социального, биологического развития [2, с. 273].

\section{2}

В нашем исследовании в рамках прагмалингвистического эксперимента речевое поведение представителей парламента Великобритании было рассмотрено в аспекте реализации эмотивно-ориентированной стратегии «участие / неучастие коммуникантов в речевом событии». Материалом для анализа послужили выступления британских женщинпарламентариев: баронессы Фолкнер (Baroness Falkner), баронессы Ройал (Baroness Royall), баронессы Стоувел (Baroness Stowell), баронессы Симэнс (Baroness Symons) (UG), и первое для Терезы Мэй (Mrs Theresa May) выступление в новой должности премьер-министра Великобритании в британском парламенте 20 июля 2016 г. (НСН).

В качестве основных методов изучения речевого поведения говорящего были приня- ты вероятностно-статистический метод и метод модифицированного контент-анализа [3]. При этом в исследуемом материале выявлено процентное содержание речевых сигналов, свидетельствующих о наличии той или иной грамматической категории. Эти процентные величины характеризуют речевой портрет конкретного говорящего (см. таблицу).

В результате эксперимента выявлено, что средний речежанровый показатель актуализации стратегии в личном плане равен $26 \%$. Представители парламента со значением этого показателя выше среднего - «лидеры по натуре» (The Prime Minister Mrs Theresa May39 \% и Baroness Falkner - 35 \%), они властны, независимы, смелы и самоуверенны. Такие люди могут игнорировать социальные условности, жить по собственным законам, активно отстаивать свою самостоятельность. Представители парламента, которые чаще актуализируют личный план стратегии «участие / неучастие коммуникантов в речевом событии», проявляют склонность к авторитарному типу речевого поведения. Особенно ярко это демонстрирует Тереза Мэй, ее отличает некоторая резкость и выпячивание собственного «я». Мы анализировали ее первое выступление в парламенте в качестве премьера, которое фактически можно характеризовать как перекрестный допрос, однако он показал, что у Британии появилась новая «железная леди».

Средний речежанровый показатель реализации социального плана стратегии $-10,8 \%$. Он практически вдвое ниже показателя реализации личного плана. Нулевое значение данного показателя в речи баронессы Фолкнер при высоком показателе реализации стратегии в личном плане свидетельствует о личностной ориентированности или 〈я〉》-центрированности ее речевого поведения. Тереза Мэй чаще ос-

Речевой портрет парламентариев в соответствии с реализацией скрытой речевой стратегии «Участие / неучастие коммуникантов в речевом событии»

\begin{tabular}{|l|c|c|c|}
\hline \multirow{2}{*}{\multicolumn{1}{|c|}{ Представитель парламента }} & \multicolumn{3}{c|}{ План реализации стратегии } \\
\cline { 2 - 4 } & личный & социальный & предметный \\
\hline Baroness Falkner & $35 \%$ & $0 \%$ & $65 \%$ \\
\hline Baroness Royall & $14 \%$ & $12 \%$ & $74 \%$ \\
\hline Baroness Stowell & $18 \%$ & $16 \%$ & $66 \%$ \\
\hline Baroness Symons & $24 \%$ & $5 \%$ & $71 \%$ \\
\hline Mrs Theresa May & $39 \%$ & $21 \%$ & $40 \%$ \\
\hline Средний речежанровый показатель & $26 \%$ & $10,8 \%$ & $63,2 \%$ \\
\hline
\end{tabular}


тальных актуализирует кооперативный тип речевого поведения, демонстрируя собеседнику открытость, вовлекая последнего в диалог. Она больше других способна устанавливать и поддерживать эмоциональные контакты с участниками общения. При актуализации социального плана ей удается заручиться дружественной поддержкой со стороны слушающих, которые, по-видимому, на уровне подсознания воспринимают говорящего как близкого им по убеждениям и жизненному опыту и начинают ему доверять. Возможно, именно такое речевое поведение позволило Терезе Мэй добиться столь высокого положения в политической элите Великобритании.

Высокие в целом показатели реализации предметного плана свидетельствуют о том, что всем парламентариям присуще стремление к концентрации на объективных обстоятельствах дела, на главном. Их выступления отличаются логичностью, организованностью и четкостью.

\section{3}

Таким образом, речевая привычка является основой речевого портрета говорящего. При этом интерпретация речевого портрета говорящего приводит к идентификации индивидуальных черт его речи, а их интерпретация - к диагностированию его личностных черт, которые проявляются в конкретном дискурсе - тексте, произнесенном им «здесь и сейчас», и которые обнаруживаются при его прагмалингвистическом анализе.

\section{СПИСОК ЛИТЕРАТУРЫ}

1. Зюбина, И. А. Прагмалингвистический аспект речевого поведения русскоговорящего и англоговорящего государственного обвинителя : дис. ... канд. филол. наук / Зюбина Ирина Анатольевна. Ростов н/Д, 2005. - 167 с.

2. Зюбина, И. А. Речевой портрет государственного обвинителя: прагмалингвистический аспект / И. А. Зюбина, Г. Г. Матвеева // Язык и речь в синхронии и диахронии. - Таганрог : Изд-во Таганрог. ин-та им. А.П. Чехова, 2014. - С. 271-276.

3. Матвеева, Г. Г. Особенности контент-анализа при обработке данных объективного прагмалингвистического эксперимента в рамках скрытой прагмалингвистики / Г. Г. Матвеева // Язык. Дис- курс. Текст : в 2 ч. - Ростов н/Д : Изд-во РГПУ, 2004. Ч. 2. - C. $125-129$.

4. Матвеева, Г. Г. Речевые привычки журналиста на примере стратегии «Акцентуация автором элементов речевого события» / Г. Г. Матвеева, А. В. Тактарова // Вестник Волжского университета имени В.Н. Татищева. - 2014. - №4 (17). - С. 252-258.

5. Матвеева, Г. Г. Скрытые грамматические значения и идентификация социального лица («портрета») говорящего : дис. ... Д-ра филол. наук / Матвеева Галина Григорьевна. - СПб., 1993. - 322 с.

6. Степанов, Ю. С. Альтернативный мир, дискурс, факт и принцип причинности / Ю. С. Степанов // Язык конца ХХ века : сб. ст. - М. : РГГУ, 1995. - C. 35-73.

\section{ИСТОЧНИКИ}

$\mathrm{HCH}$ - House of Commons Hansard. 20.07.2016. - Electronic text data. - Mode of access: https://hansard.parliament.uk/commons/20160720/ debates/16072025000019/Engagements (date of access: 31.07.2016). - Title from screen.

$U G$ - Ukraine (Shooting Down of MH17) and Gaza. Statement. - Electronic text data. - Mode of access: http://www.publications.parliament.uk/pa/ ld201415/ldhansrd/text/140721-0002.htm\# 14072118000102 (date of access: 31.07.2016). - Title from screen.

\section{REFERENCES}

1. Zyubina I.A. Pragmalingvisticheskiy aspekt rechevogo povedeniya russkogovoryashchego $i$ anglogovoryashchego gosudarstvennogo obvinitelya: dis. ... kand. filol. nauk [Pragmalinguistic Aspect of Russian-Speaking and English-speaking Public Prosecutor Speech Behavior. Cand. philol. sci. diss.]. Rostov-on-Don, 2005. 167 p.

2. Zyubina I.A., Matveeva G.G. Rechevoy portret gosudarstvennogo obvinitelya: pragmalingvisticheskiy aspekt [Speech Portrait of the Public Prosecutor: Pragmalinguistic Aspect]. Yazyk $i$ rech $v$ sinkhronii i diakhronii [Language and Speech in Synchrony and Diachrony]. Taganrog, Izd-vo Taganrog. in-ta imeni A.P. Chehova, 2014, pp. 271-276.

3. Matveeva G.G. Osobennosti kontent-analiza pri obrabotke dannykh obyektivnogo pragmalingvisticheskogo eksperimenta $\mathrm{v}$ ramkakh skrytoy pragmalingvistiki [Peculiarities of Content Analysis in Processing Data of Objective Pragmalinguistic Experiment within Implicit Pragmalinguistics]. Yazyk. Diskurs. Tekst. V 2 ch. Ch. 2 [Language. Discourse. Text. In 2 parts. Part 2]. Rostov-onDon, Izd-voRGPU, 2004, pp. 125-129. 


\section{ГЛАВНАЯ ТЕМА НОМЕРА}

4. Matveeva G.G., Taktarova A.V. Rechevye privychki zhurnalista na primere strategii «Aktsentuatsiya avtorom elementov rechevogo sobytiya» [Journalist's Speech Habits on the Example of the Strategy "Accentuation of the Speech Event Elements by the Author"]. Vestnik Volzhskogo universiteta imeni V.N. Tatishheva, 2014, no. 4(17), pp. 252-258.

5. Matveeva G.G. Skrytye grammaticheskie znacheniya $i$ identifikatsiya sotsialnogo litsa ("portreta») govoryashchego: dis. ... d-rafilol. nauk [Implicit Grammatical Meanings and Identification of Speaker's Social Face ("Portrait"). Dr. philol. sci. diss.]. Saint Petersburg, 1993. $322 \mathrm{p}$.

6. Stepanov Yu.S. Alternativnyy mir, diskurs, fakt i printsip prichinnosti [Alternative World,
Discourse, Fact and Causality Principle]. Yazyk kontsa XX veka: sb. statey [Language of XX Century End: collection of articles]. Moscow, RGGU Publ., 1995, pp. 35-73.

\section{SOURCES}

House of Commons Hansard. 20.07.2016. Available at: https://hansard.parliament.uk/commons/ 2016-07-20/debates/16072025000019/Engagements. (accessed July 31, 2016).

Ukraine (Shooting Down of MH17) and Gaza. Statement. Available at: http://www.publications. parliament.uk/pa/ld201415/ldhansrd/text/1407210002. htm\#14072118000102. (accessed July 31, 2016).

\section{Information About the Authors}

Galina G. Matveeva, Doctor of Sciences (Philology), Professor, Department of German Philology, Southern Federal University, Bolshaya Sadovaya St., 33, 344082 Rostov-on-Don, Russian Federation, gegemat2337633@rambler.ru.

Irina A. Zyubina, Candidate of Sciences (Philology), Associate Professor, Department of Linguistics and Professional Communication, Southern Federal University, Bolshaya Sadovaya St., 33, 344082 Rostovon-Don, Russian Federation, irinazyubina@gmail.com.

\section{Информация об авторах}

Галина Григорьевна Матвеева, доктор филологических наук, профессор кафедры немецкой филологии, Южный федеральный университет, ул. Большая Садовая, 33, 344082 г. Ростовна-Дону, Российская Федерация, gegemat2337633@rambler.ru.

Ирина Анатольевна Зюбина, кандидат филологических наук, доцент кафедры лингвистики и профессиональной коммуникации, Южный федеральный университет, ул. Большая Садовая, 33, 344082 г. Ростов-на-Дону, Российская Федерация, irinazyubina@gmail.com. 